\title{
SOCRATES
}

\section{SOCRATES episode II (synopsis of cochrane reviews applicable to emergency services episode II): the return of the series II}

\author{
P Gilligan, J Lee, A Khan, P Jennings, J Cooper, D Hegarty, G Lumsden, D Godden, A Pountney, \\ B Wilson, M Shepherd, L Allonby-Neve, C Mehigan, E Kidney, A Broderick, S Carr, S Wilson, \\ J O'Sullivan
}

Emerg Med J 2007;24:115-117. doi: 10.1136/emj.2006.038018

"Sir William Osler (1849-1919) said, In science credit goes to the man who convinces the world, not to the man to whom the idea first occurs"

$T^{T}$ he desire to provide the highest possible level of care to all our patients is one of the primary motivations of emergency physicians. The scope of our practice is such that we need to be aware of the developments in most other specialties. The Cochrane Database continues to provide the world with rigorous analysis of research and thus gives us the opportunity to use this information in the best interests of our patients.

In this synopsis Of Cochrane Reviews applicable to emergency services (SOCRATES), we will look at the reviews that we found in our assessment of the output of the Cochrane Heart Group.

\section{METHODS}

The method used to find and summarise the reviews is as described previously. We found eight reviews from the Cochrane Heart Group that we thought were of particular relevance.

\section{ACTIVE CHEST COMPRESSION-DECOMPRESSION FOR CARDIOPULMONARY RESUSCITATION \\ Background}

The objective of this review was to determine whether active compression-decompression cardiopulmonary resuscitation (CPR) using a handheld suction device improved outcome (mortality) compared with standard manual CPR in adult patients with cardiac arrest. The secondary outcome measure was complications of $\mathrm{CPR}$-for example, rib fractures or pneumothorax.

\section{Results}

Eight out-of-hospital studies $(\mathrm{n}=4162)$, one in-hospital study $(\mathrm{n}=53)$ and one study with both in-hospital and out-ofhospital components $(n=773)$ were included. No difference was found in mortality, survival to discharge or complications between the active compression-decompression CPR group and the standard manual CPR group.

\section{SOCRATES says}

Active compression-decompression CPR does not improve the outcome of adult patients with cardiac arrest when compared with standard manual CPR.

- Lafuente-Lafuente C, Melero-Bascones M. Active chest compression-decompression for cardiopulmonary resuscitation. (Cochrane Review). In: Cochrane Library, Issue 2. Oxford: Update Software, 2006.

\begin{abstract}
ANTICOAGULANTS OR ANTIPLATELET TREATMENT FOR NON-RHEUMATIC ATRIAL FIBRILLATION AND FLUTTER

Background

Patients with atrial fibrillation and atrial flutter are at an increased risk of stroke. This review aimed to identify randomised controlled trials of drugs used to prevent thromboembolism in adults with non-postoperative, non-rheumatic atrial fibrillation in order to quantify the risk of stroke, major haemorrhage and death for patients using each drug.
\end{abstract}

\section{Results}

Fourteen studies were included. Warfarin was significantly more effective than placebo for primary stroke prevention (odds ratio (OR) $0.30,95 \%$ confidence interval (CI) 0.19 to 0.48 ), but conferred an increased risk for major bleeding (OR 1.90, 95\% CI 0.89 to 4.04). Aspirin was more effective than placebo for stroke prevention (OR $0.68,95 \%$ CI 0.29 to 1.57 ), without increasing the risk for major bleeding (OR 0.81, 95\% CI 0.37 to 1.78 ), but the confidence intervals were wide and spanned an OR of 1.

\section{SOCRATES says}

The evidence strongly supports warfarin for stroke prevention in patients with atrial fibrillation. Decisions regarding warfarin for patients at increased risk of haemorrhage (eg, alcoholism, previous gastrointestinal bleed) should be made on an individual basis. The evidence for aspirin in stroke prevention is inconclusive.

- Segal JB, McNamara RL, Miller MR, et al. Anticoagulants or antiplatelet therapy for non-rheumatic atrial fibrillation and flutter. In: Cochrane Library, Issue 2. Oxford: Update Software, 2006.

\section{CONTINUOUS INFUSION VERSUS BOLUS INJECTION OF LOOP DIURETICS IN CONGESTIVE HEART FAILURE Background}

Bolus injection of loop diuretics, given to patients with acute decompensated heart failure, may cause fluctuations in intravascular volume and increased toxicity. Continuous infusion is proposed to avoid such complications. This review aimed to identify randomised controlled trials that compared the effects and adverse effects of a continuous intravenous infusion of loop diuretics with bolus intravenous administration in patients with congestive heart failure class III-IV.

\section{Results}

Eight trials $(n=254)$ were included. Urine output was greater in patients who were given a continuous infusion, with a mean difference of $271 \mathrm{ml} / 24 \mathrm{~h}, 95 \%$ CI 93.1 to 449 . Fewer adverse effects (tinnitus and hearing loss) were noted when continuous 
infusion was given (relative risk $0.06,95 \%$ CI 0.01 to 0.44 ). Allcause mortality and electrolyte disturbances (hypokalemia, hypomagnesaemia) were not significantly different in the two treatment groups.

\section{SOCRATES says}

This review showed a greater diuresis and a better safety profile when loop diuretics were given by continuous infusion. However, the small size and relative heterogeneity of the included studies means that the results are unlikely to alter current practice.

- Salvador DRK, Rey NR, Ramos GC, et al. Continuous infusion versus bolus injection of loop diuretics in congestive heart failure. In: Cochrane Library, Issue 2. Oxford: Update Software, 2006.

\section{ELECTRICAL CARDIOVERSION FOR ATRIAL FIBRILLATION AND FLUTTER \\ Background}

Electrical cardioversion has been used since the 1960s in attempts to convert atrial fibrillation to sinus rhythm. This review aimed to identify controlled trials that compared electrical cardioversion with non-electrical attempts to control atrial fibrillation or flutter. Outcome measures included risk of stroke, mortality, quality of life and the risk of rehospitalisation.

\section{Results}

There were three completed trials on electrical cardioversion (rhythm control) versus rate control, with a total of 927 participants. No difference was found in mortality between the two treatment strategies (OR 0.83 , CI 0.48 to 1.43 ). There seemed to be a trend towards more strokes in the rhythm control group (OR 1.9, 95\% CI 0.99 to 3.64). On follow-up, physical functioning, physical role function and vitality were significantly better in the rhythm control group in two of the studies.

\section{SOCRATES Says}

Electrical cardioversion (rhythm control) led to a non-significant increase in stroke risk but was found to improve three domains of quality of life.

- Mead GE, Elder AT, Flapan AD, et al. Electrical cardioversion for atrial fibrillation and flutter. In: Cochrane Library, Issue 2. Oxford: Update Software, 2006.

\section{PHARMACOLOGICAL CARDIOVERSION FOR ATRIAL FIBRILLATION AND FLUTTER Background}

Approaches to the management of atrial fibrillation include control of the ventricular rate or conversion to sinus rhythm. This review aimed to identify controlled clinical trials of pharmacological cardioversion versus rate control in adults with acute, paroxysmal or sustained atrial fibrillation or atrial flutter. Outcome measures included the annual risk of stroke, peripheral embolism and mortality.

\section{Results}

Two completed studies were included, Atrial Fibrillation Follow-up Investigation of Rhythm Management $(n=4060)$ and Pharmacological Intervention in Atrial Fibrillation $(n=252)$. No difference was found in mortality between rhythm control and rate control (RR 1.14, 95\% CI 1.00 to 1.31). Both studies show significantly higher rates of hospitalisation and adverse events in the rhythm control group but no difference in quality of life between the two treatment groups. In Atrial Fibrillation Follow-up Investigation of Rhythm
Management, there was a similar incidence of ischaemic stroke, bleeding and systemic embolism in the two groups.

\section{SOCRATES says}

No evidence suggests that pharmacological cardioversion of atrial fibrillation to sinus rhythm reduces the risk of stroke or mortality. Rhythm control is associated with more adverse effects and increased hospitalisation.

- Cordina J, Mead G. Pharmacological cardioversion for atrial fibrillation and flutter. In: Cochrane Library, Issue 2. Oxford: Update Software, 2006.

\section{LOW MOLECULAR WEIGHT HEPARINS VERSUS UNFRACTIONATED HEPARIN FOR ACUTE CORONARY SYNDROMES \\ Background}

This review aimed to identify randomised controlled clinical trials to determine the relative safety and efficacy of subcutaneous low-molecular-weight heparins (LMWH) versus intravenous unfractionated heparin (UFH) for people with acute coronary syndromes (ACS; unstable angina or non-ST segment elevation myocardial infarction).

\section{Results}

Seven studies ( $\mathrm{n}=11092$ ) were included. No difference was found in overall mortality between the groups treated with LMWH and UFH (RR 1.0, 95\% CI: 0.69 to 1.44). LMWH reduced the occurrence of myocardial infarction (RR 0.83 , 95\% CI 0.70 to 0.99 ) and the need for revascularisation procedures ( $\mathrm{RR}=0.88,95 \%$ CI 0.82 to 0.95$)$. A decrease in the incidence of thrombocytopenia (RR $0.64,95 \%$ CI 0.44 to 0.94 ) was noted in patients who were given LMWH. No evidence was found for difference in occurrence of recurrent angina, or major or minor bleeds.

\section{SOCRATES says}

LMWH should be used rather than UFH in ACS. Insufficient data exist to recommend a single form of $\mathrm{LMWH}$.

- Magee KD, Sevcik W, Moher D, et al. Low molecular weight heparins versus unfractionated heparin for acute coronary syndromes. In: Cochrane Library, Issue 2. Oxford: Update Software, 2006.

\section{PLATELET GLYCOPROTEIN IIB/IIIA BLOCKERS FOR PERCUTANEOUS CORONARY REVASCULARIZATION, AND UNSTABLE ANGINA AND NON-ST-SEGMENT ELEVATION MYOCARDIAL INFARCTION} Background

Glycoprotein IIB/IIA antagonists inhibit platelet aggregation and may prevent vessel occlusion. This review aimed to identify randomised controlled clinical trials comparing intravenous Glycoprotein IIb/IIIa blockers and standard medical treatment with standard medical treatment alone for percutaneous coronary revascularisation or unstable angina or non-ST segment elevation myocardial infarction to determine their safety and efficacy.

\section{Results}

Fourteen trials were included, with 17788 patients receiving percutaneous coronary revascularisation. Glycoprotein IIb/IIIa blockers were associated with a significant reduction in risk of death or infarction both at 30 days (OR 0.62, CI 0.55 to 0.70 ) and at 6 months (OR 0.65 , CI 0.58 to 0.73 ), but with an increased risk of severe bleeding (OR 1.38, CI 1.04 to 1.85). Eight trials were included, with 30006 patients with unstable angina or non-ST segment elevation myocardial infarction. Glycoprotein IIb/IIIa blockers were associated with a smaller 
reduction in risk of death or infarction at both 30 days (OR 0.91 , CI 0.85 to 0.98 ) and at 6 months (OR 0.88, CI 0.81 to $0.95)$ ), and a slight by increased risk of severe bleeding (OR 1.27, CI 1.12 to 1.44 ).

\section{SOCRATES says}

Glycoprotein IIb/IIIa blockers reduce the risk of death or infarction in patients receiving percutaneous coronary revascularisation. The benefit of Glycoprotein IIb/IIIa blockers in patients with unstable angina or non-ST segment elevation myocardial infarction is less clear, and local or national cardiology guidance should be followed.

- Bosch X, Marrugat J. Platelet glycoprotein IIb/IIIa blockers for percutaneous coronary revascularization, and unstable angina and non-ST-segment elevation myocardial infarction. In: The Cochrane Library, Issue 2. Oxford: Update software, 2006.

\section{HYPERBARIC OXYGEN THERAPY FOR ACUTE CORONARY SYNDROME Background}

Hyperbaric oxygen treatment (HBOT) may improve oxygen supply to the heart in patients with ACS and reduce the extent of cardiac muscle necrosis. This review aimed to identify randomised controlled clinical trials comparing the effect on ACS of regimens that include HBOT with those that exclude HBOT.

\section{Results}

Four trials ( $\mathrm{n}=462$ ) were included. There was a trend towards, but no significant decrease in, the risk of death with HBOT (RR $0.64,95 \%$ CI 0.38 to 1.06 ). Evidence from individual trials showed reductions in the risk of major adverse coronary events (RR $0.12,95 \%$ CI 0.02 to 0.85 ), and showed that the time to relief of pain was reduced with HBOT. About 15\% of patients in one trial complained of claustrophobia in a single occupancy chamber.

\section{SOCRATES says}

Individual small trials suggest that the addition of HBOT reduced the risk of major adverse cardiac events and the time to relief from ischaemic pain, but did not significantly reduce mortality. Given the technical difficulties associated with HBOT, its use for patients with ACS cannot be justified on the basis of this review.

- Bennett M, Jepson N, Lehm JP. Hyperbaric oxygen therapy for acute coronary syndrome. In: Cochrane Library, Issue 2. Oxford: Update Software, 2006.

\section{CONCLUSION}

In this the second article of SOCRATES Episode II the results of the search of the Cochrane Heart Group have been presented. In the next article we will present the synopses relating to urology and musculoskeletal medicine.

\section{Authors' affiliations}

P Gilligan, A Broderick, S Carr, Beaumont Hospital, Dublin, Ireland

J Lee, York Hospital, York, UK

A Khan, Bradford Royal Infirmary, Bradford, UK

P Jennings, D Godden, A Pountney, B Wilson, L Allonby-Neve,

C Mehigan, E Kidney, The Yorkshire Rotation, Yorkshire, UK

J Cooper, G Lumsden, St James's University Hospital, Leeds, UK

D Hegarty, Ballymun, Dublin, Ireland

M Shepherd, Pinderfield Hospital, Wakefield, UK

S Wilson, Bristol, UKI

J O'Sullivan, Mater Hospital, Dublin, Ireland

Competing interests: None.

All authors are part of the SOCRATES Episode II Working Party.

Correspondence to: P Gilligan, Beaumont Hospital, Beaumont Road, Dublin D9, Ireland; peadargilligan@beaumont.ie

Accepted 2 May 2006 